Original

\title{
Assessment of dental maturity of children aged 3.5 to 13.5 years using the Demirjian method in an Iranian population
}

\author{
Ali Bagherian ${ }^{1)}$ and Mostafa Sadeghi ${ }^{2)}$ \\ ${ }^{1)}$ Department of Pediatric Dentistry, School of Dentistry, Rafsanjan University of Medical Science, \\ Rafsanjan, Iran \\ ${ }^{2}$ Department of Restorative Dentistry, School of Dentistry, Rafsanjan University of Medical Science, \\ Rafsanjan, Iran
}

(Received 9 August and accepted 16 December 2010)

\begin{abstract}
Radiographs of developing teeth are commonly used to assess dental maturity. The method for assessment of dental maturity first described by Demirjian is widely used and accepted. The aim of this study was to assess the accuracy of the Demirjian method in an Iranian population in order to compare the difference in dental maturity between these children with the data obtained in Canadian children and to determine whether there is a correlation between dental maturity and BMI-for-age. In this study, the orthopantomographs of 519 healthy children ( 264 boys and 255 girls) aged 3.5-13.5 years were reviewed and the dental age was determined by the Demirjian method. The chronological ages of the children were obtained by subtracting their birthdates from the date of taking the radiograph. Height and weight measurements were also recorded and the data were analyzed using SPSS-16 software. The Demirjian method overestimated the age by 0.15 and 0.21 years in boys and girls, respectively. Paired $t$-test analysis showed that these differences were statistically significant $(P=0.001)$. The increase in mean age difference initiated from the underweight group towards the overweight group, but this correlation was not statistically significant $(P=0.094)$. Based on the amount of differences between estimated dental age and chronological age in this investigation, the Demirjian
\end{abstract}

Correspondence to Dr. Ali Bagherian, Department of Pediatric Dentistry, School of Dentistry, Rafsanjan University of Medical Science, P. O. Box: 334, Rafsanjan, Iran

Tel: +98-391-8220031-4

Fax: +98-391-8220008

E-mail: drbagherian@yahoo.com method seems to be clinically applicable in the Iranian population. (J Oral Sci 53, 37-42, 2011)

Keywords: Demirjian method; chronological age; dental age; BMI-for-age index; Iranian population.

\section{Introduction}

Dental age assessment has an important role in forensic medicine, pediatric dentistry and orthodontic treatment planning (1). Orthodontists use such knowledge to predict the timing of particular treatments and pediatricians may be interested in knowing whether the dental maturity of a child with a certain disease has been delayed or advanced (2-4). Although there are skeletal, dental and sexual maturity indicators, dental maturity indicators have received more attention because they exhibit less variability compared with sexual and skeletal age estimation methods that are more affected by the endocrine and nutritional status of children and adolescents (5-7). Dental age can be assessed mainly by two methods: I) according to the status of tooth emergence in the oral cavity, and II) according to the stages of tooth formation observed in radiographs. The first method is not preferred because it cannot be used in children with a complete primary dentition who have not yet reached a mixed dentition. On the other hand, the second method can be used over longer periods of time and is less affected by local factors such as premature loss of deciduous teeth, ankylosis or arch size deficiency for permanent teeth $(6,8)$.

In 1973, Demirjian introduced a dental age assessment method (9) based on the stages of tooth development in 
panoramic radiographs. This method has been widely used in different populations (1,6,8,10-16). Mani et al. employed the Demirjian dental age estimation method in 7- to 15-year-old Malays and reported that this method overestimated the age by 0.75 and 0.61 years among boys and girls, respectively. They recommended further modification of the Demirjian method for the Malay population (6). Hegde et al. evaluated dental age in 6- to 13-year-old children from Belgaum, India by the Demirjian method and reported a weak overestimation of 0.14 and 0.04 years for boys and girls, respectively and concluded that this method was applicable in Belgaum children (12).

Bagherpour et al. (17) recently assessed dental age using the Demirjian method among Iranian children and found that this method overestimated the age of boys by 0.34 years and girls by 0.25 years. The aim of this study was to assess the Demirjian method in a larger sample size with greater age range of an Iranian population in order to compare the difference in dental maturity between these children and the data obtained in French-Canadian children by Demirjian (18) and also to determine whether there is a correlation between dental maturity and BMI-for-age.

\section{Materials and Methods}

In this cross-sectional study, 519 children (264 boys and 255 girls) were selected from children referred to the Oral and Maxillofacial Radiology department of Rafsanjan Dental School to take panoramic radiographs (orthopantomographs). The protocol was reviewed and approved by the Medical Research Ethics Committee of the Rafsanjan University of Medical Sciences.

The inclusion criteria were:

- Age between 3.5 to 13.5 years-old

- No history of congenital and systemic disorders

- Resident of Rafsanjan City

- No missing left permanent mandibular teeth

- Parental permission (written informed consent)

All orthopanthomographs were scored by one examiner using the Demirjian method (9) to obtain dental age. Fifty subjects were re-examined after 2 weeks by the examiner. Intra-examiner reproducibility was assessed using the Cohen's Kappa statistics for repeated maturity scores and was found to be 0.95 .

In this method, seven left permanent mandibular teeth were scored "0" for lack of calcification and "A" to " $\mathrm{H}$ " depending on the stage of calcification. Standards were given for each sex separately and the sum of scores of dental maturity was converted to dental age by a conversion table. The scores used in this study were the revised scores published by Demirjian and Goldstein (18).

The chronological ages of the children were obtained by subtracting the birthdates from the date the radiograph was taken and converted into years with two decimals. The children were also divided into 10 groups according to their chronological age. The sample size of each group was calculated based on data from a pilot study in 74 children and it was determined that at least 19 children of each sex should be in each group to detect a 1-year difference between the dental age and chronological age with a precision of 5\% and the largest standard deviation of 0.7 year in age difference (10.5-11.49 year-old age group; girls).

Body weight of children was recorded to the nearest 0.1 $\mathrm{kg}$ using a standard beam balance scale (Hopeway Industrial Ltd., Guangdong, China) with the children wearing lightweight clothing and no shoes. Body height of children was recorded to the nearest centimeter according to the following protocol: no shoes, heels together and head positioned in the Frankfurt plane and touching a ruler. All the measurements were done by the same person.

Body mass index (weight/height in $\mathrm{kg} / \mathrm{m}^{2}$ ) was calculated and compared with the international gender-and-age specific charts for BMI-for-age determination (19). In children, BMI-for-age is classified as underweight, normalweight, at risk of overweight and overweight. Underweight is defined as BMI-for-age $<5$ th percentile, normal-weight 5 th percentile $\leq$ BMI-for-age $<85$ th percentile, at risk of overweight 85 th percentile $\leq$ BMI-for-age $<95$ th percentile, and overweight BMI-for-age $\geq 95$ th percentile (20).

All data were statistically analyzed by SPSS- 16 software. The differences between the chronological age and the estimated dental age were statistically analyzed using the paired $t$-test and Wilcoxon signed rank test. Spearman's rho was used to assess the correlation between BMI-forage and mean age differences. A $P$ value less than 0.05 was considered to be statistically significant.

\section{Results}

The mean and SD of chronological age, dental age and dental age minus chronological age of children were 8.35 \pm 2.71 years (boys: $8.31 \pm 2.68$, girls: $8.40 \pm 2.73$ ), 8.54 \pm 2.55 years (boys: $8.46 \pm 2.50$, girls: $8.61 \pm 2.60$ ), and $0.19 \pm 0.50$ years (boys: $0.15 \pm 0.51$, girls: $0.21 \pm 0.49$ ), respectively. Independent $t$-test showed that there was no statistically significant difference between boys and girls.

Tables 1 and 2 indicate the comparison of dental age using the Demirjian method and chronological age in boys and girls, respectively. In boys, overestimation was noted in five age groups and underestimation in the other five groups. Overestimation was more common in younger children, but underestimation was common in older age groups (except the 10.5-11.49 year-old age group). In 
Table 1 Comparison between chronological age and dental age in boys

\begin{tabular}{ccccccc}
\hline \multirow{2}{*}{ Age group $(n)$} & \multicolumn{3}{c}{ Mean (SD) } & $\begin{array}{c}95 \% \text { CI of } \\
\text { age difference }\end{array}$ & $P$ value $^{\ddagger}$ & $P$ value $^{¥}$ \\
\cline { 2 - 5 } & Chronological age & Dental age & Age difference $^{\ddagger}$ & & \\
\hline $3.5-4.49(24)$ & $4.17(0.27)$ & $4.74(0.51)$ & $0.57(0.38)$ & $0.41,0.73$ & 0.001 & 0.001 \\
$4.5-5.49(29)$ & $5.06(0.28)$ & $5.46(0.44)$ & $0.40(0.33)$ & $0.28,0.53$ & 0.001 & 0.001 \\
$5.5-6.49(23)$ & $5.99(0.27)$ & $6.61(0.46)$ & $0.62(0.35)$ & $0.47,0.77$ & 0.001 & 0.001 \\
$6.5-7.49(31)$ & $6.95(0.31)$ & $7.40(0.66)$ & $0.45(0.51)$ & $0.26,0.63$ & 0.001 & 0.001 \\
$7.5-8.49(39)$ & $8.17(0.26)$ & $8.02(0.46)$ & $-0.14(0.42)$ & $-0.28,-0.01$ & 0.039 & 0.045 \\
$8.5-9.49(28)$ & $8.93(0.27)$ & $8.87(0.62)$ & $-0.06(0.50)$ & $-0.26,0.13$ & 0.526 & 0.608 \\
$9.5-10.49(27)$ & $10.05(0.27)$ & $9.96(0.61)$ & $-0.09(0.44)$ & $-0.26,0.09$ & 0.312 & 0.681 \\
$10.5-11.49(22)$ & $10.88(0.25)$ & $11.03(0.48)$ & $0.14(0.35)$ & $-0.02,0.30$ & 0.075 & 0.057 \\
$11.5-12.49(20)$ & $12.10(0.30)$ & $11.98(0.69)$ & $-0.13(0.48)$ & $-0.35,0.10$ & 0.262 & 0.478 \\
$12.5-13.50(21)$ & $12.93(0.24)$ & $12.78(0.33)$ & $-0.15(0.25)$ & $-0.26,-0.04$ & 0.013 & 0.015 \\
Total $(264)$ & $8.31(2.68)$ & $8.46(2.50)$ & $0.15(0.51)$ & $0.09,0.22$ & 0.001 & 0.001 \\
\hline
\end{tabular}

${ }^{\dagger}$ Dental age minus chronological age; ${ }^{\ddagger}$ paired t-test; ${ }^{\ddagger}$ Wilcoxon signed rank test; CI: confidence interval; SD: standard deviation

Table 2 Comparison between chronological age and dental age in girls

\begin{tabular}{lcccccc}
\hline \multirow{2}{*}{ Age group $(n)$} & \multicolumn{3}{c}{ Mean (SD) } & $\begin{array}{c}95 \% \text { CI of } \\
\text { age difference }\end{array}$ & $P$ value $^{\ddagger}$ & $P$ value $^{¥}$ \\
\cline { 2 - 5 } & Chronological age & Dental age & Age difference $^{\dagger}$ & & \\
\hline $3.5-4.49(19)$ & $4.23(0.31)$ & $4.54(0.51)$ & $0.31(0.35)$ & $0.14,0.48$ & 0.001 & 0.002 \\
$4.5-5.49(27)$ & $5.03(0.30)$ & $5.42(0.53)$ & $0.39(0.48)$ & $0.20,0.58$ & 0.001 & 0.001 \\
$5.5-6.49(33)$ & $6.01(0.28)$ & $6.67(0.53)$ & $0.66(0.36)$ & $0.54,0.79$ & 0.001 & 0.001 \\
$6.5-7.49(29)$ & $7.01(0.27)$ & $7.42(0.45)$ & $0.41(0.43)$ & $0.24,0.57$ & 0.001 & 0.001 \\
$7.5-8.49(25)$ & $8.03(0.30)$ & $7.89(0.48)$ & $-0.13(0.47)$ & $-0.33,0.06$ & 0.165 & 0.192 \\
$8.5-9.49(31)$ & $8.97(0.29)$ & $9.11(0.51)$ & $0.15(0.39)$ & $0.01,0.29$ & 0.042 & 0.027 \\
$9.5-10.49(25)$ & $10.11(0.31)$ & $10.12(0.63)$ & $0.10(0.56)$ & $-0.22,0.24$ & 0.925 & 0.819 \\
$10.5-11.49(19)$ & $10.87(0.34)$ & $10.99(0.36)$ & $0.12(0.42)$ & $-0.08,0.33$ & 0.211 & 0.058 \\
$11.5-12.49(26)$ & $12.01(0.31)$ & $12.01(0.38)$ & $0.01(0.34)$ & $-0.14,0.14$ & 0.982 & 0.517 \\
$12.5-13.50(21)$ & $13.05(0.30)$ & $13.09(0.48)$ & $0.04(0.44)$ & $-0.16,0.24$ & 0.687 & 0.444 \\
Total $(255)$ & $8.40(2.73)$ & $8.61(2.60)$ & $0.21(0.49)$ & $0.16,0.28$ & 0.001 & 0.001 \\
\hline
\end{tabular}

${ }^{\dagger}$ Dental age minus chronological age; ${ }^{\ddagger}$ paired t-test; ${ }^{\ddagger}$ Wilcoxon signed rank test; CI: confidence interval; SD: standard deviation

girls, there was obvious overestimation in nine groups and underestimation in only one group (7.5-8.49 year-old age group). Also, before the age of 8.5 , boys were more advanced or equal in dental age compared to girls, but after this age the overestimation in girls became more frequent. The mean age difference between dental age determined using the Demirjian method (from the French-Canadian children) and the chronological age of these Iranian children was 0.15 years $(\mathrm{SD}=0.51)$ for boys and 0.21 years $(\mathrm{SD}$ $=0.49$ ) for girls, and paired $t$-test analysis showed that these differences were statistically significant $(P=0.001)$. This result shows that the dental age of the Iranian children compared to their chronological age was higher by 0.15 years ( 55 days) in boys and 0.21 years ( 77 days) in girls.

Figures 1 and 2 demonstrate the distribution of estimated dental age by the Demirjian method in comparison with chronological age in boys and girls, respectively. They show that overestimation was slightly more common than underestimation in both boys and girls.

The mean and SD of height, weight and BMI of children were $1.29 \pm 0.15 \mathrm{~m}$ (boys: $1.29 \pm 0.17$, girls: $1.29 \pm 0.14$ ), $27.90 \pm 9.59 \mathrm{~kg}$ (boys: $28.29 \pm 9.72$, girls: $27.49 \pm 9.46$ ), and $16.28 \pm 2.65 \mathrm{~kg} / \mathrm{m}^{2}$ (boys: $16.45 \pm 2.72$, girls: $16.11 \pm$ 2.57), respectively. Table 3 demonstrates that the mean age difference between the estimated age by Demirjian and the chronological age increased from the underweight group towards the overweight group, but the Spearman's rho test indicated that this correlation was not statistically significant $(P=0.094)$.

\section{Discussion}

Developing teeth in radiographs are frequently used to assess dental maturity and estimate age. In clinical dentistry, these data are useful in diagnosis and treatment planning $(21,22)$. The proximity of a computed value to its real value and the reproducibility of a method are important factors in assessing dental age. Since Demirjian's tooth development stages are one of the most detailed, using the relative length of the crown and root instead of their length, the reproducibility of dental age estimation with this 


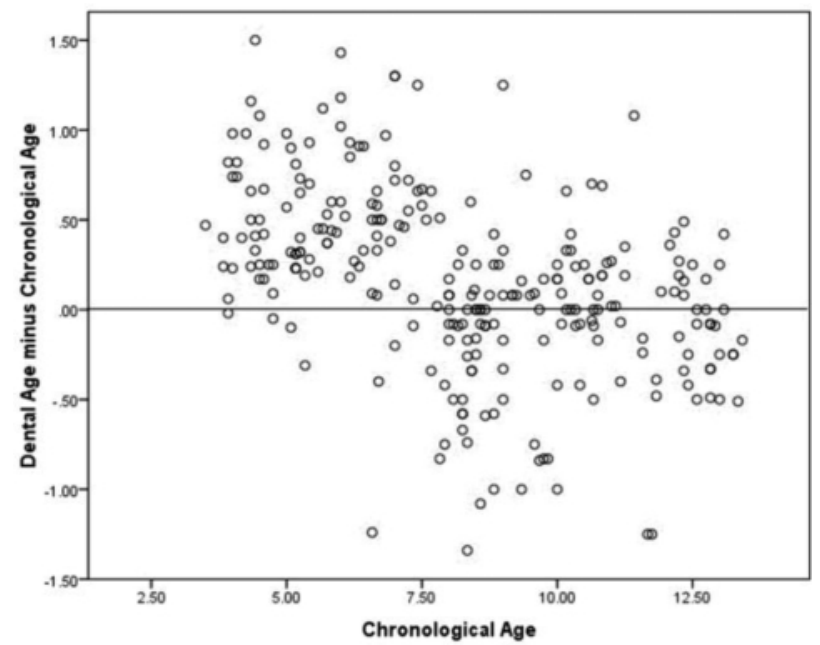

Fig. 1 Distribution of estimated dental age in comparison with chronological age in boys.

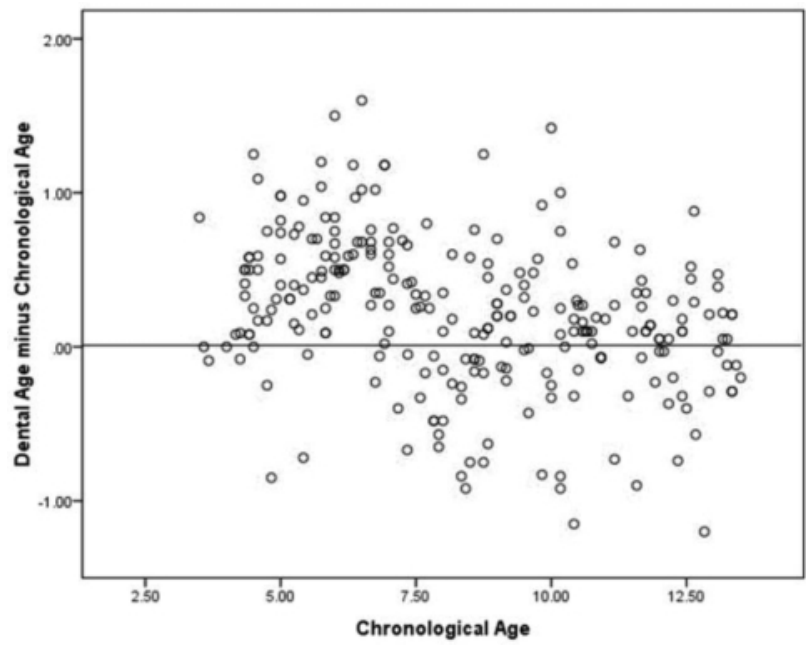

Fig. 2 Distribution of estimated dental age in comparison with chronological age in girls.

Table 3 Comparison of age differences in each category of BMI-for-age

\begin{tabular}{|c|c|c|c|c|c|c|c|c|}
\hline \multirow{2}{*}{ BMI-for-age $(n)$} & \multicolumn{2}{|c|}{$\begin{array}{c}\text { Gender }(n) \\
(\%)\end{array}$} & \multicolumn{3}{|c|}{ Mean (SD) } & \multirow{2}{*}{$\begin{array}{c}95 \% \mathrm{CI} \text { of } \\
\text { age difference }\end{array}$} & \multirow{2}{*}{$P$ value ${ }^{+}$} & \multirow{2}{*}{$P$ value } \\
\hline & Boy & Girl & Chronological age & Dental age & Age difference ${ }^{\dagger}$ & & & \\
\hline Underweight (94) & $\begin{array}{c}49 \\
(52.1)\end{array}$ & $\begin{array}{c}45 \\
(47.9)\end{array}$ & $7.61(2.70)$ & $7.76(2.46)$ & $0.15(0.53)$ & $0.04,0.26$ & 0.007 & 0.005 \\
\hline Normal-weight (352) & $\begin{array}{c}168 \\
(47.7)\end{array}$ & $\begin{array}{c}184 \\
(52.3)\end{array}$ & $8.48(2.72)$ & $8.66(2.58)$ & $0.17(0.49)$ & $0.12,0.23$ & 0.001 & 0.001 \\
\hline At risk of overweight (57) & $\begin{array}{c}34 \\
(59.6)\end{array}$ & $\begin{array}{c}23 \\
(40.4)\end{array}$ & $8.84(2.54)$ & $9.12(2.37)$ & $0.28(0.46)$ & $0.15,0.40$ & 0.001 & 0.001 \\
\hline Overweight (16) & $\begin{array}{c}13 \\
(81.2) \\
\end{array}$ & $\begin{array}{c}3 \\
(18.8)\end{array}$ & $8.08(2.31)$ & $8.39(2.03)$ & $0.31(0.60)$ & $-0.01,0.63$ & 0.053 & 0.069 \\
\hline
\end{tabular}

Dental age minus chronological age; ${ }^{*}$ paired t-test; ${ }^{*}$ Wilcoxon signed rank test; CI: confidence interval; SD: standard deviation

method is very good $(2,6,22)$. Therefore, the method devised by Demirjian et al. is widely used.

Tooth development has variations among populations and these differences exist between several worldwide ethnic groups, even between cities in the same country (23). Therefore, this study was performed to compare the dental age assessment of a group of children living in Rafsanjan (a city located geographically in the central part of Iran having a population of around 300,000) with the FrenchCanadian children of Demirjian's study.

In the present study, it was observed that Iranian children in this age group were significantly advanced in dental maturation $[0.15$ years ( 55 days) for boys and 0.21 years (77 days) for girls]. Previously, several studies investigated the suitability of the Demirjian method in populations that differed from Canadians (1,6-8,10,12-16,22,24,25). All of these studies have demonstrated that the Demirjian method overestimated age between 0.04 years (12) to 3.04 years (1). According to the opinion of the authors, this advancement in dental maturation may be partly explained by the positive secular trend in growth and development observed during the last 35 years $(6,8,13,14,26-28)$. Other differences between the populations can be explained by environmental factors such as socio-economic status, nutrition, dietary habits and lifestyle (1).

In this study, on comparison between the mean values of differences between estimated ages and chronological ages in both sexes, boys were more advanced before the age of 8.5 years, which may indicate that boys are slightly more advanced in overall body growth than girls in this period; however, thereafter, the girls caught up with the boys and their dental development was more advanced than the boys. This finding can be explained by earlier prepubertal and pubertal growth changes that occur in that age period in girls.

Eid et al. (8) and Koshy and Tandon (1) discovered a 
greater overestimation in older age groups, while in the present study it was found that overestimation was more common in younger age groups. Thus, the present study was in agreement with the study by Maber et al. (22), which also did not observe that age in younger children could be more accurately predicted than older children. These differences can be explained by difference in sample size, method of age calculation, age groups, the age and sex distribution of the original study population and statistical methodologies.

Another focus of this study was to assess the correlation between the different categories of BMI-for-age and dental maturity. Age and gender specific BMI values for children are referred to as "BMI-for-age". BMI-for-age is adopted by the World Health Organization as the most specific nutritional status evaluation method. The categories describing body fat for children and teenagers are also different from the categories describing adult body fat. It includes underweight, normal-weight, at risk of overweight and overweight, but there is no obese category for children (20).

In this study, the mean advancement of dental age from chronological age increased from the underweight group towards the overweight group, but the correlation was not statistically significant. This finding is in agreement with Eid et al. (8), but Mani et al. (6) found a positive correlation between the BMI and overestimation of age in boys using Willem's method, and Hilgers et al. (29) found that accelerated dental development was seen in overweight children. These findings indicated that nutritional status may have an effect on dental maturity, but it is a minor effect and any certain role of BMI in connection with this remains unknown.

Based on the amount of differences between estimated dental age and chronological age in this investigation, the Demirjian method seems to be clinically applicable in the Iranian population and nutritional status may have a minor influence on dental maturity.

\section{Acknowledgments}

The authors express their gratitude to Dr. E Soltanimehr for her assistance in this research. This study was supported by a grant from the Vice Chancellor of Research of Rafsanjan University of Medical Sciences.

\section{References}

1. Koshy S, Tandon S (1998) Dental age assessment: the applicability of Demirjian's method in south Indian children. Forensic Sci Int 94, 73-85.

2. Butti AC, Clivio A, Ferraroni M, Spada E, Testa A, Salvato A (2009) Häävikko's method to assess dental age in Italian children. Eur J Orthod 31, 150155.

3. Hauk MJ, Moss ME, Weinberg GA, Berkowitz RJ (2001) Delayed tooth eruption: association with severity of HIV infection. Pediatr Dent 23, 260-262.

4. Lehtinen A, Oksa T, Helenius H, Rönning O (2000) Advanced dental maturity in children with juvenile rheumatoid arthritis. Eur J Oral Sci 108, 184-188.

5. Demirjian A, Buschang PH, Tanguay R, Patterson DK (1985) Interrelationships among measures of somatic, skeletal, dental, and sexual maturity. Am J Orthod 88, 433-438.

6. Mani SA, Naing L, John J, Samsudin AR (2008) Comparison of two methods of dental age estimation in 7-15-year-old Malays. Int J Paediatr Dent 18, 380388.

7. Nykänen R, Espeland L, Kvaal SI, Krogstad O (1998) Validity of the Demirjian method for dental age estimation when applied to Norwegian children. Acta Odontol Scand 56, 238-244.

8. Eid RM, Simi R, Friggi MN, Fisberg M (2002) Assessment of dental maturity of Brazilian children aged 6 to 14 years using Demirjian's method. Int J Paediatr Dent 12, 423-428.

9. Demirjian A, Goldstein H, Tanner JM (1973) A new system of dental age assessment. Hum Biol 45, 211-227.

10. Davis PJ, Hägg U (1994) The accuracy and precision of the "Demirjian system" when used for age determination in Chinese children. Swed Dent J 18, 113-116.

11. Hägg U, Matsson L (1985) Dental maturity as an indicator of chronological age: the accuracy and precision of three methods. Eur J Orthod 7, 25-34.

12. Hegde RJ, Sood PB (2002) Dental maturity as an indicator of chronological age: radiographic evaluation of dental age in 6 to 13 years children of Belgaum using Demirjian methods. J Indian Soc Pedod Prev Dent 20, 132-138.

13. Leurs IH, Wattel E, Aartman IH, Etty E, PrahlAndersen B (2005) Dental age in Dutch children. Eur J Orthod 27, 309-314.

14. Liversidge HM, Speechly T, Hector MP (1999) Dental maturation in British children: are Demirjian's standards applicable? Int J Paediatr Dent 9, 263-269.

15. Prabhakar AR, Panda AK, Raju OS (2002) Applicability of Demirjian's method of age assessment in children of Davangere. J Indian Soc Pedod Prev Dent 20, 54-62.

16. Willems G, Van Olmen A, Spiessens B, Carels C (2001) Dental age estimation in Belgian children: 
Demirjian's technique revisited. J Forensic Sci 46, 893-895.

17. Bagherpour A, Imanimoghaddam M, Bagherpour MR, Einolghozati M (2010) Dental age assessment among Iranian children aged 6-13 years using the Demirjian method. Forensic Sci Int 197, 121.e1-4.

18. Demirjian A, Goldstein H (1976) New systems for dental maturity based on seven and four teeth. Ann Hum Biol 3, 411-421.

19. Heird WC (2007) Overweight and obesity. In: Nelson textbook of pediatrics, 18th ed, Kliegman RM, Behrman RE, Jenson HB, Stanton BF eds, Saunders Elsevier, Philadelphia, 232-242.

20. Macek MD, Mitola DJ (2006) Exploring the association between overweight and dental caries among US children. Pediatr Dent 28, 375-380.

21. Liversidge HM, Lyons F, Hector MP (2003) The accuracy of three methods of age estimation using radiographic measurements of developing teeth. Forensic Sci Int 131, 22-29.

22. Maber M, Liversidge HM, Hector MP (2006) Accuracy of age estimation of radiographic methods using developing teeth. Forensic Sci Int 159, Suppl 1, 68-73.

23. Nyström M, Ranta R, Kataja M, Silvola H (1988) Comparisons of dental maturity between the rural community of Kuhmo in northeastern Finland and the city of Helsinki. Community Dent Oral Epidemiol 16, 215-217.

24. Chaillet N, Nyström M, Kataja M, Demirjian A (2004) Dental maturity curves in Finnish children: Demirjian's method revisited and polynomial functions for age estimation. J Forensic Sci 49, 1324-1331.

25. Nyström M, Haataja J, Kataja M, Evälahti M, Peck L, Kleemola-Kujala E (1986) Dental maturity in Finnish children, estimated from the development of seven permanent mandibular teeth. Acta Odontol Scand 44, 193-198.

26. Foti B, Lalys L, Adalian P, Giustiniani J, Maczel M, Signoli M, Dutour O, Leonetti G (2003) New forensic approach to age determination in children based on tooth eruption. Forensic Sci Int 132, 4956.

27. Holtgrave EA, Kretschmer R, Müller R (1997) Acceleration in dental development: fact or fiction. Eur J Orthod 19, 703-710.

28. Nadler GL (1998) Earlier dental maturation: fact or fiction? Angle Orthod 68, 535-538.

29. Hilgers KK, Akridge M, Scheetz JP, Kinane DF (2006) Childhood obesity and dental development. Pediatr Dent 28, 18-22. 